\title{
Slow Wave Sleep Is a Promising Intervention Target for Alzheimer's Disease
}

\author{
Yee Fun Lee 1,2 , Dmitry Gerashchenko ${ }^{3}$, Igor Timofeev ${ }^{4,5}$, Brian J. Bacskai' and \\ Ksenia V. Kastanenka ${ }^{1 *}$ \\ ${ }^{1}$ Department of Neurology, MassGeneral Institute of Neurodegenerative Diseases, Massachusetts General Hospital \\ and Harvard Medical School, Charlestown, MA, United States, ${ }^{2}$ Department of Anatomy and Neurobiology, Boston \\ University School of Medicine, Boston, MA, United States, ${ }^{3}$ Harvard Medical School/NA Boston Healthcare System, West \\ Roxbury, MA, United States, ${ }^{4}$ Department of Psychiatry and Neuroscience, School of Medicine, Université Laval, Québec, \\ QC, Canada, ${ }^{5}$ CERVO Brain Research Center, Québec, QC, Canada
}

Alzheimer's disease (AD) is the major cause of dementia, characterized by the presence of amyloid-beta plaques and neurofibrillary tau tangles. Plaques and tangles are associated with sleep-wake cycle disruptions, including the disruptions in non-rapid eye movement (NREM) slow wave sleep (SWS). Alzheimer's patients spend less time in NREM sleep and exhibit decreased slow wave activity (SWA). Consistent with the critical role of SWS in memory consolidation, reduced SWA is associated with impaired memory consolidation in AD patients. The aberrant SWA can be modeled in transgenic mouse models of amyloidosis and tauopathy. Animal models exhibited slow wave impairments early in the disease progression, prior to the deposition of amyloid-beta plaques, however, in the presence of abundant oligomeric amyloid-beta. Optogenetic rescue of SWA successfully halted the amyloid accumulation and restored intraneuronal calcium levels in mice. On the other hand, optogenetic acceleration of slow wave frequency exacerbated amyloid deposition and disrupted neuronal calcium homeostasis. In this review, we summarize the evidence and the mechanisms underlying the existence of a positive feedback loop between amyloid/tau pathology and SWA disruptions that lead to further accumulations of amyloid and tau in AD. Moreover, since SWA disruptions occur prior to the plaque deposition, SWA disruptions may provide an early biomarker for AD. Finally, we propose that therapeutic targeting of SWA in AD might lead to an effective treatment for Alzheimer's patients.

Keywords: Alzheimer's disease, sleep, NREM sleep, slow wave activity, slow oscillations

\section{INTRODUCTION}

Alzheimer's disease (AD) is a progressive neurodegenerative disorder and the most common cause of dementia in the elderly (Alzheimer's Association, 2016). The pathological hallmarks of $\mathrm{AD}$ are the presence of extracellular plaques composed of amyloid-beta $(\mathrm{A} \beta)$ and intracellular neurofibrillary tangles composed of the microtubule binding protein tau in the brain (Bloom, 2014; Calderon-Garcidueñas and Duyckaerts, 2017). According to the amyloid cascade hypothesis, $A \beta$ accumulation leads to tau deposition, triggers neuronal dysfunction and results in neuronal 
death (Hardy and Higgins, 1992; Selkoe and Hardy, 2016). Although, amyloid cascade hypothesis is widely debated, soluble $\mathrm{A} \beta$ and tau protein aggregations have been shown to lead to synaptic dysfunction and loss of synaptic density (SpiresJones and Hyman, 2014), resulting in memory and cognitive deficits in AD patients (DeKosky and Scheff, 1990). The clinical features of $\mathrm{AD}$ include progressive memory loss, impaired judgment and decision-making (Förstl and Kurz, 1999). Current therapeutics are limited to alleviation of symptoms, not reversing or slowing the disease progression (Yiannopoulou and Papageorgiou, 2013; Cummings et al., 2019). Therefore, there is an urgent need to identify effective treatment strategies for alleviating the disease burden.

In addition to memory and cognitive impairments, Alzheimer's patients experience sleep disruptions (Bliwise et al., 1995; McCurry et al., 1999; Moran et al., 2005), leading to reductions of non-rapid eye movement (NREM) sleep and slow wave activity (SWA), a brain rhythm prevalent during NREM sleep (Prinz et al., 1982). These disruptions include increased amounts and frequencies of nighttime wakefulness as well as daytime napping (Vitiello and Prinz, 1989; McCurry et al., 1999). Sleep disturbances manifest early since individuals with mild cognitive impairment (MCI), a pre-clinical stage of AD, suffer from sleep disruptions (Vitiello and Prinz, 1989; Westerberg et al., 2012). Similarly, individuals with detectable amyloid beta, but cognitively healthy also suffer from sleep disturbances, defined as lower sleep quality and increased number of day-time naps (Ju et al., 2013). Thus, sleep and memory disruptions manifest early in the disease progression, prior to symptom onset.

Sleep mediates several forms of memory consolidation (Diekelmann and Born, 2010; Born and Wilhelm, 2012; Rasch and Born, 2013). Sleep disturbances are correlated with deteriorated memory function and cognitive decline in $\mathrm{AD}$ and MCI patients (Moe et al., 1995; Brzecka et al., 2018). Increased night-time wakefulness and decreased slow wave sleep (SWS), which is dominated by SWA, was associated with impaired memory and cognitive functions (Moe et al., 1995). NREM, in particular SWS, plays an important role in declarative memory consolidation (Walker, 2009; Lu and Göder, 2012). This review will provide an overview of the SWA disruptions in $\mathrm{AD}$. It will also summarize the evidence for the causal relationship between $\mathrm{AD}$ pathology, $\mathrm{A} \beta /$ tau, and sleep-dependent memory consolidation deficits that are driven by the SWA disturbances in $\mathrm{AD}$ patients and animal models of AD. Furthermore, we will propose possible mechanisms underlying the SWA disruptions. Finally, we will discuss therapeutic strategies for targeting SWS in $\mathrm{AD}$ aimed at slowing the disease progression and restoring the sleep-dependent memory consolidation. This review is focused on the SWA, the most prominent neocortical activity with the increased power density in $0.5-4.0 \mathrm{~Hz}$ frequency range occurring during NREM sleep. It will not cover other NREM sleep-associated rhythms, such as thalamo-cortical sleep spindles, or hippocampal ripples, nor will it discuss REM sleep disruptions in $\mathrm{AD}$, that have been reviewed or described elsewhere (Christos, 1993; Rauchs et al., 2008; Pase et al., 2017).

\section{SWA AND SLEEP-DEPENDENT MEMORY CONSOLIDATION}

Sleep consists of rapid eye movement (REM) and NREM sleep. REM sleep is characterized by desynchronized EEG activity with faster oscillations and lower voltage waveforms (Carskadon and Dement, 2011). Human NREM sleep is subdivided into stages N1-N3 (previously stages 1-4) and is defined by the electroencephalogram (EEG) activity as synchronous waveforms, including sleep spindles $(12-14 \mathrm{~Hz}), \mathrm{K}$-complexes in stage 2 as well as slow $(<1 \mathrm{~Hz})$ and delta $(1-4 \mathrm{~Hz})$ activity in stage 3 (Iber et al., 2007). Slow and delta oscillations or isolated slow waves are commonly called SWA (Timofeev et al., 2020). Stage N3, also referred to as Delta Sleep or SWS, is characterized by the high amounts of SWA (Carskadon and Dement, 2011).

Slow oscillation is a major rhythm of deep sleep. During slow oscillations, excitatory and inhibitory neocortical neurons from all layers (unknown for layer 1) in anesthetized (Steriade et al., 1993a,b,c) and sleeping animals (Timofeev et al., 2000b, 2001; Steriade et al., 2001; Chauvette et al., 2010) oscillate between depolarized (active or UP) and hyperpolarized (silent or DOWN) states. Despite involvement of the entire thalamocortical system (Steriade et al., 1993a; Contreras and Steriade, 1995; Sheroziya and Timofeev, 2014), the slow oscillations originate in neocortex as can be recorded in neocortical slices (Sanchez-Vives and McCormick, 2000; Sanchez-Vives et al., 2010), cortical cell cultures (Sun et al., 2010; Hinard et al., 2012) and isolated cortical slabs maintained in vivo (Timofeev et al., 2000a; Lemieux et al., 2014). Slow oscillation is absent from the thalamus of decorticated animals (Timofeev and Steriade, 1996). The silent (hyperpolarized or DOWN) states of slow oscillations are periods of disfacilitation, i.e., absence of synaptic activity. Leak currents primary mediate silent states (Timofeev et al., 1996, 2001). The active (depolarized or up) states are mediated by barrages of excitatory and inhibitory synaptic activities at the level of soma (Steriade et al., 2001; Timofeev et al., 2001; Rudolph et al., 2007) and major $\mathrm{Ca}^{2+}$ activities in dendrites (Milojkovic et al., 2007; Seibt et al., 2017). Neocortex generates slow oscillations while thalamus contributes to their maintenance as thalamic inactivation temporally modifies cortical SWA (David et al., 2013; Lemieux et al., 2014).

To control the slow oscillations, it is important to understand the major cellular events taking place during SWA. The neuronal firing and thus synaptic activity in local cortical networks, is essentially absent in the silent state. Two major mechanisms for the active state onset are proposed. (i) The silent state is partially mediated by $\mathrm{Ca}^{2+}$ - and $\mathrm{Na}^{+}$-dependent $\mathrm{K}^{+}$currents. A reduction in these currents leads to the onset of a new active state (Sanchez-Vives and McCormick, 2000). (ii) Silent states are characterized by the absence of synaptic activity, but spikeindependent neurotransmitter release (miniature postsynaptic potentials, minis) are still present. Co-occurrence of minis in large neurons that possess a high number of postsynaptic sites 
can lead to significant depolarizations and initiations of spikes, that would drive the whole network into an active state (Timofeev et al., 2000a; Bazhenov et al., 2002; Chauvette et al., 2010). Since this is a stochastic process, it can start in any cell, but more often, it starts in larger neurons, typically layer 5 large cortical pyramidal cells in experimental animals (Chauvette et al., 2010; Fiáth et al., 2016). In human, however, slow wave active states more often start in layer 3 (Cash et al., 2009; Csercsa et al., 2010). There might be two reasons for this difference: (a) human pyramidal cells from layer 3 are very large (Mohan et al., 2015), and therefore, they are well situated to summate minis and to trigger active states; and (b) enhanced electrical compartmentalization in layer 5 pyramidal neurons in humans does not allow dendritic depolarizing events to reach soma, even in the presence of dendritic spikes (Beaulieu-Laroche et al., 2018), therefore reducing overall implication of layer 5 cells in network operation. Local origin of active states and dense synaptic interactions in the cortex trigger propagation of slow waves across cortical mantle (Massimini et al., 2004; Volgushev et al., 2006; Sheroziya and Timofeev, 2014). Active states are mediated by interactions of excitatory and inhibitory conductances (Haider et al., 2006; Haider and McCormick, 2009; Chen et al., 2012) with overall stronger inhibition at the level of soma (Rudolph et al., 2007; Haider et al., 2013). A termination of active states and transition to silent states occurs due to several factors: (i) activation of $\mathrm{Na}^{+}-$and $\mathrm{Ca}^{2+}$ dependent potassium currents (Sanchez-Vives and McCormick, 2000), (ii) synaptic depression (Timofeev et al., 2000b), and (iii) synchronous active inhibitory drive (Steriade et al., 1993b; Lemieux et al., 2015). Because active states terminate nearly simultaneously across large cortical territories (Volgushev et al., 2006; Sheroziya and Timofeev, 2014), intrinsic current activation or synaptic depression likely do not play a leading role, because they are cell specific. Thus, we suggest that active inhibitory mechanisms terminate active states and provide network-wide synchronous onset of silent states. First, somatostatin-positive GABAergic interneurons increase activity prior to the onset of silent states (Funk et al., 2017; Niethard et al., 2018). Most of these interneurons have short axons, therefore an external trigger, possibly from thalamus, synchronizes them. Indeed, thalamic inactivation abolishes synchronous onset of silent states (Lemieux et al., 2015). Furthermore, some thalamocortical neurons fire during silent states driving parvalbumin-positive interneurons (Zucca et al., 2019). Another potential source is claustrum, the structure that has widespread cortical projections and, if activated optogenetically, induces cortical down states (Narikiyo et al., 2018). It appears that claustrum is well situated to drive simultaneously cortical interneurons across different areas just prior to the onset of silent states.

Sleep slow oscillations play an important role in cortical plasticity. However, the direction of these plastic changes is still under discussion. A subset of studies, based mainly on indirect measurements, propose that cortical synaptic connections are strengthened during wakefulness and are weakened during sleep (Tononi and Cirelli, 2003, 2014). Other studies demonstrate that slow oscillations and overall sleep strengthens efficacy of cortical synapses (Aton et al., 2009; Chauvette et al., 2012; Seibt et al., 2012; Yang et al., 2014; Jasinska et al., 2015; Timofeev and Chauvette, 2017). Finally, there is an attempt to reach agreement in this debate which proposes that some synapses are upregulated and others are downregulated by sleep (Seibt and Frank, 2019).

Irrespective of the synaptic mechanisms, slow oscillations play an important role in sleep-dependent declarative memory consolidation (Steriade and Timofeev, 2003; Marshall et al., 2006; Walker, 2009; Lu and Göder, 2012). Born and colleagues proposed a model of declarative, hippocampus-related memory consolidation during SWS. Cortical slow oscillations drive the reactivation of short-term hippocampal memories by synchronizing hippocampal sharp wave ripples with spindle activity in the thalamus during slow oscillation UP states. This mechanism thereby contributes to the long-term synaptic plasticity changes in neocortical networks and supports the consolidation of long-term memory in neocortex (Diekelmann and Born, 2010; Rasch and Born, 2013). SWS declines with increasing age especially after the age of 30 (Van Cauter et al., 2000). Age-related reduction in SWS was correlated with impaired sleep-associated memory consolidation (Backhaus et al., 2007). Furthermore, insomnia patients with less SWS showed declines in overnight declarative memory consolidation compared to age-matched controls (Backhaus et al., 2006). Boosting SWA facilitated sleep-dependent memory consolidation (Marshall et al., 2006). Thus, SWA, slow oscillations in particular, is necessary and sufficient for memory consolidation during sleep, and we propose that SWA disruptions might contribute to memory impairments in $\mathrm{AD}$.

\section{SWA DISRUPTIONS IN AD PATIENTS}

Toxic $A \beta$ is thought to initiate pathological events and drive the formation of pathological tau aggregates that ultimately lead to synaptic loss and cell death (Hardy and Higgins, 1992; Selkoe and Hardy, 2016; Henstridge et al., 2019), which in turn compromises neuronal circuitry. $A \beta$ levels correlate with sleep alterations in cognitively normal individuals with preclinical AD (Ju et al., 2013; Spira et al., 2013). Neuronal activity disturbances including slow oscillation disruptions were reported in older adults (Mander et al., 2013, 2015; Lucey et al., 2019). A $\beta$ and tau deposits were associated with decreased NREM SWA in cognitively normal older adults and in early stages of $\mathrm{AD}$ (Mander et al., 2015; Lucey et al., 2019). Decreased NREM slow oscillations $(0.6-1 \mathrm{~Hz})$ were associated with increased $\mathrm{A} \beta$ accumulation in the medial prefrontal cortex (Mander et al., 2015). Also, higher tau deposition was correlated with decreased delta power $(1-4 \mathrm{~Hz})$ (Lucey et al., 2019). This evidence provides strong support for a relationship between SWA disruptions and AD pathology (Figure 1). In addition to SWA disruptions in asymptomatic cognitively normal adults, SWA was reduced in MCI individuals (Westerberg et al., 2012). Sleep disturbances in cognitively normal older adults could predict the $\mathrm{A} \beta$ burden and tau accumulation later in life (Winer et al., 2019). Taking into account all of the above, we propose that, sleep-wake cycle disturbances, especially decreases in NREM SWA, may serve as a potential early biomarker for $\mathrm{AD}$. 


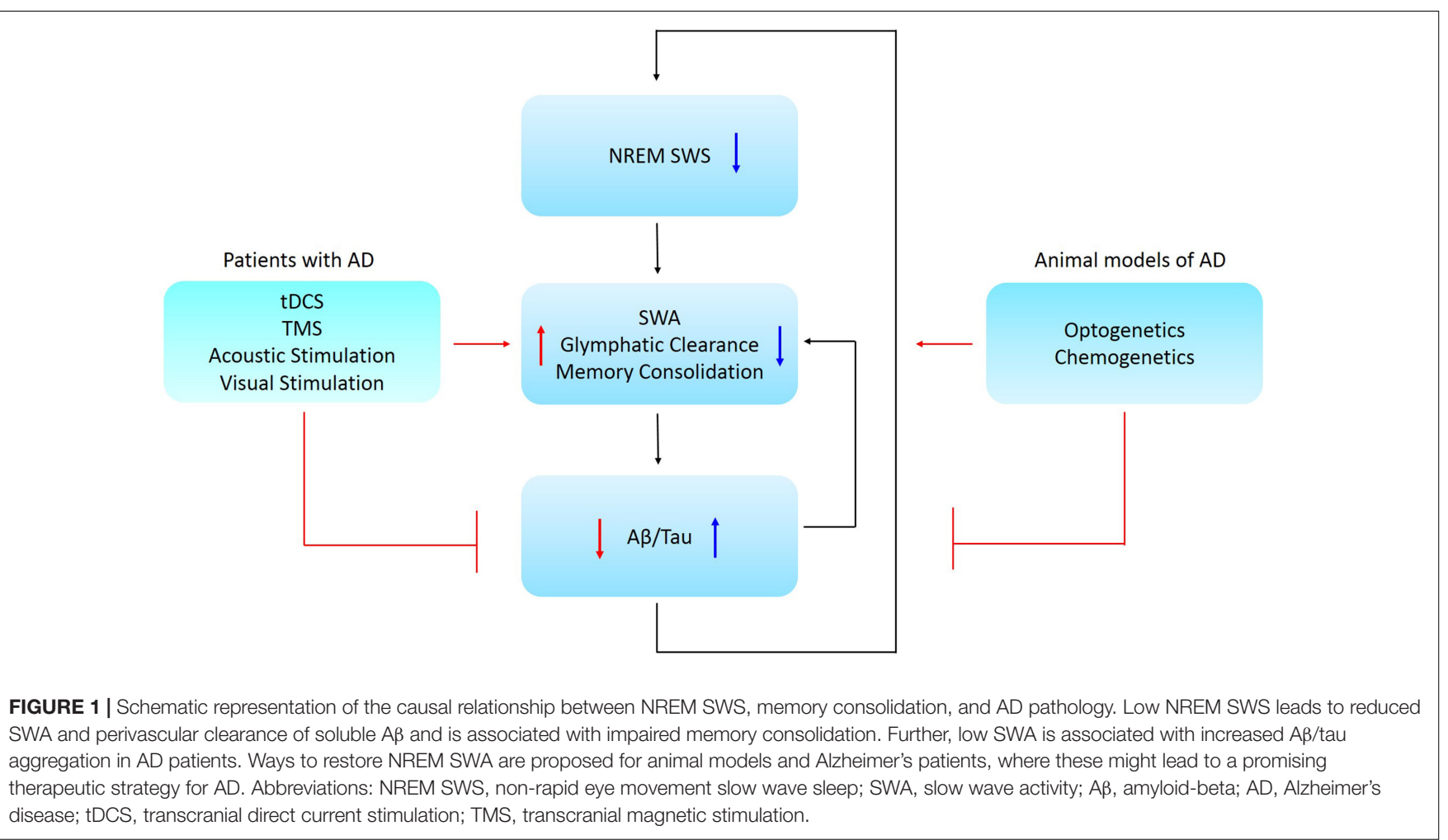

Aberrations in SWA correlated with disrupted memory consolidation in MCI patients (Westerberg et al., 2012) and older adults (Mander et al., 2015). Therefore, it stands to reason that slow oscillation disruptions in individuals with early $\mathrm{AD}$ might contribute to and accelerate the progressive memory and cognitive decline. In turn, AD pathology might further disrupt sleep-dependent brain rhythm activity that further exacerbates AD (Figure 1).

Glymphatic system hypothesis, although still debated (Abbott et al., 2018), states that soluble $A \beta$ is cleared along perivascular pathways, including through the glymphatic system (Iliff et al., 2012). SWS enhanced the clearance of $A \beta$ when compared to the waking state (Xie et al., 2013). Interestingly, soluble $A \beta$ levels fluctuated with the sleep-wake cycle in humans. $A \beta$ levels were elevated during waking and declined during sleep (Kang et al., 2009; Lucey et al., 2017), suggesting that sleep facilitates A $\beta$ clearance. Thus, there is accumulating evidence for a relationship between $A \beta$, sleep and neuronal activity disruptions (Figure 1).

\section{SWA DISRUPTIONS IN MOUSE MODELS OF AD}

Mouse models of AD provide a powerful means to study SWA disruptions. Amyloidosis models recapitulate A $\beta$ production, amyloid plaque deposition and associated neuropathology exhibited by Alzheimer's patients. Tauopathy models mimic tau production, intracellular tau tangles and associated neuropathology. Furthermore, slow oscillation disruptions were recapitulated in mouse models of amyloidosis and tauopathy
(Holth et al., 2017; Kastanenka et al., 2017; Castano-Prat et al., 2019). Wide field imaging using voltage sensitive dyes (VSD) and genetically encoded reporters, in addition to traditional methods, such as electrophysiology, allowed monitoring SWA in mice. Similar to those in humans (Massimini et al., 2004), slow oscillations propagate across cortex in mice as traveling waves between two hemispheres (Mohajerani et al., 2010). We used a transgenic mouse model of amyloidosis (APPswe/PS1dE9 mice; APP mice) to show that the cortical slow wave power but not the frequency was decreased in young (Kastanenka et al., 2017) and older mice (Kastanenka et al., 2019). APP mice spent less time in NREM sleep (Roh et al., 2012). Tg2576 mice exhibited decreases in SWA; and their power spectral density was shifted to higher frequencies (Kent et al., 2018). As for tauopathy models, P301S human tau transgenic mice exhibited sleep-wake cycle disruptions, reductions in NREM sleep and increased wakefulness. Moreover, their SWA was significantly decreased during NREM sleep (Holth et al., 2017). Furthermore, the transgenic mouse model 3xTg-AD, which develops plaque and tangle pathology, exhibited slow waves at lower frequency and reduced firing rate (Castano-Prat et al., 2019). Thus, these animal models recapitulated SWA disruptions exhibited by Alzheimer's patients (Lucey et al., 2019). It should be noted that animal models do not recapitulate all aspects of human condition. Mice have more primitive cortex and hence slow oscillations present in mice are not as complex as those recorded in humans. During aging, sleep in mice undergoes changes, sometimes dissimilar to those in humans. For example, aged mice exhibit less SWS compared to young mice. The power of slow-wave activity in aging mice is increased when measured in frontal cortex, while 
slow wave power in aging human adults is decreased. On the other hand, aging mice also exhibit similarities to aging humans. For example, aged mice exhibit increases in sleep fragmentation, increases in sleep duration during active phase of sleep-wake cycle (light for humans, dark for mice), and decreased REM sleep at the end of quiet phase of sleep-wake cycle (Soltani et al., 2019). Thus use of mouse models should be considered with caution when modeling human condition. Despite these limitations, the mouse models were successfully used to monitor and modulate activity of specific neuronal and non-neuronal populations that contribute to the disruptions of slow waves (see below). Uncovering the neural circuit mechanisms that underlie the SWA disruptions could lead to the discovery of novel therapeutic strategies.

\section{MECHANISMS UNDERLYING SWA DISRUPTIONS IN AD}

Observations from human studies demonstrated that disrupted SWA contributed to the impairments of memory consolidation in $\mathrm{AD}$ patients. However, the mechanisms that underlie SWA disruptions remain largely unknown. A $\beta$ peptides target synapses and disrupt excitatory and inhibitory neurotransmission leading to neural network dysfunction (Selkoe, 2019). This indicates that, SWA anomalies in aMCI and AD patients might be due to the neuronal network dysfunction resulting from neuronal hyperand hypoactivity. Animal studies using multiphoton microscopy elucidated deficits in inhibitory tone as one possible mechanism for disrupted SWA (Busche et al., 2008; Kastanenka et al., 2017). Deficits in synaptic inhibition led to neuronal hyperactivity (Busche et al., 2008) and caused desynchronized circuit activity within cortical excitatory neurons (Kastanenka et al., 2017). More than $20 \%$ of the layer $2 / 3$ cortical neurons exhibited hyperactivity surrounding $A \beta$ plaques. This hyperactivity was reduced when hyperactive neurons were treated with the gammaaminobutyric acid $\mathrm{A}\left(\mathrm{GABA}_{\mathrm{A}}\right)$ agonist diazepam (Busche et al., 2008), while slow oscillations were rescued by topical application of GABA directly onto the somatosensory cortex (Kastanenka et al., 2017). In addition to low GABA levels, the expression of $\mathrm{GABA}_{\mathrm{A}}$ and $\mathrm{GABA}_{\mathrm{B}}$ receptors was downregulated in APP mice (Kastanenka et al., 2017). Interestingly, application of either $\mathrm{GABA}_{\mathrm{A}}$ or $\mathrm{GABA}_{\mathrm{B}}$ inhibitors disrupted slow oscillations in healthy wild-type animals, mimicking slow wave disruptions in APP mice (Kastanenka et al., 2017). As we indicated earlier, GABAergic neurons play a critical role in the onset of cortical silent states, the major element of SWA. Topical applications of a $\mathrm{GABA}_{\mathrm{A}}$ receptor agonist rescued slow waves and sleepdependent memory consolidation in transgenic mice (Busche et al., 2015). Thus, APP mice exhibit cortical hyper- and hypoactivity due to deficits in inhibitory elements of the circuit, specifically GABA, GABA $A$, and $\mathrm{GABA}_{\mathrm{B}}$ receptors, the activity of which is necessary and sufficient for normal SWA.

Alzheimer's disease is a truly progressive disorder. Deficits in inhibitory elements of the circuit were followed by deficits in excitatory elements (Kastanenka et al., 2019). The protein levels of the cortical excitatory neurotransmitter glutamate were examined in APP mice. Glutamate levels were comparable in APP and wild-type littermates at 7 months of age (Kastanenka et al., 2017). However, by 9 months of age, APP mice started showing deficits in glutamate levels (Kastanenka et al., 2019). These findings indicate that the disturbances of synaptic inhibition followed by a deficiency in synaptic excitation within the neuronal circuits may be related to the disruptions of slow oscillations in AD. Furthermore, administration of the glutamate receptor antagonists alleviated hyperactivity in APP mice (Busche et al., 2008). Taken together, inhibition deficits followed by excitation deficits within the slow wave circuits most likely contributed to the disruption of slow oscillations early in the disease progression and impaired sleep-dependent memory formation.

In addition to inhibitory and excitatory neurons, corticothalamic circuits rely on astrocytes to maintain their normal function (Araque et al., 1999; Poskanzer and Yuste, 2011, 2016). Astrocytes are the glial cells that maintain glutamate and GABA recycling via glutamate/GABA-glutamine cycles. Astrocytes form the tripartite synapses with pre- and post-synaptic neuronal compartments to regulate synaptic transmission via astrocytic calcium signaling (Araque et al., 1999; Newman, 2003). Astrocytic contributions to normal circuit function has been underappreciated until recently (Clarke and Barres, 2013; Kastanenka et al., 2020). Amyloid deposits disrupted astrocytic topology (Galea et al., 2015), and astrocytic calcium dynamics were altered in APP mice (Kuchibhotla et al., 2009). Furthermore, elevations in resting calcium concentrations were reported in astrocytes in APP mice (Kuchibhotla et al., 2009). Thus, aberrant astrocytic activity might contribute to the SWA disruptions in AD. Furthermore, the protein expression levels of glutamate transporters GLAST and GLT-1, which localize specifically to astrocytic plasma membrane, were decreased in the cortex and hippocampus in a mouse model of AD (Schallier et al., 2011). Alterations in astrocytic elements of the circuit were also reported in brain tissue from $\mathrm{AD}$ patients. The expression of astrocytic glutamine synthetase was decreased in close proximity to $\mathrm{A} \beta$ plaques in $\mathrm{AD}$ brains (Robinson, 2000). Interestingly, aberrant expression of glutamine synthetase was detected in a subpopulation of pyramidal neurons in AD individuals (Robinson, 2000), suggesting that the glutamateglutamine cycle was disrupted. The abnormalities in astrocytic activity may contribute to aberrant neuronal firing and lead to the disruption of neuronal networks, thus perturbing SWA. Indeed, astrocytes participated in triggering slow oscillation UP states in vitro (Poskanzer and Yuste, 2011) and in vivo (Poskanzer and Yuste, 2016; Szabó et al., 2017). Poskanzer and Yuste (2016) visualized intracellular calcium transients and demonstrated that astrocytes had modulated extracellular glutamate, thus triggering the SWA in mouse brains. Furthermore, Szabó et al. (2017) showed that blocking astrocytic calcium transients resulted in reduced numbers of astrocytes and neurons participating in the SWA. This series of studies supports the idea that astrocytes are necessary and play a critical role in induction of slow oscillation UP states in the cortical circuits. Therefore, astrocytic network studies using animal models are important to understand the role of astrocytes in slow wave dysfunction in AD. Finally, 
understanding the role of astrocytes in SWA disruptions might point to a novel therapeutic strategy for Alzheimer's patients.

\section{OPTOGENETIC CONTROL OF SLOW OSCILLATIONS IN MOUSE MODELS OF AD}

Optogenetics is a leading-edge research tool that can be used to gain valuable insight into the causal relationship between circuit dynamics and Alzheimer's progression using animal models (Boyden et al., 2005; Li et al., 2005). This methodology provides high spatiotemporal precision with cell-type specificity. Distinct cell types can be targeted in vivo using cell-type specific promoters with light-activatable channels or proton pumps (Fenno et al., 2011). Light activation of cells expressing the channels or pumps can be used to manipulate the activity within neural circuits of interest. Optogenetics has been successfully adopted to studies of AD using mouse models.

Optogenetics was used to increase neuronal activity chronically in hippocampal perforant pathway in $\mathrm{AD}$ mice. This exacerbated hyperactivity in the circuit and increased interstitial fluid $\mathrm{A} \beta 42$ levels as well as $\mathrm{A} \beta$ deposition in the projection areas (Yamamoto et al., 2015). Optogenetic-mediated increases in neuronal activity also elevated release and propagation of tau in htau mice (Wu et al., 2016). This evidence further solidified the fact that aberrant synaptic activity facilitated $\mathrm{AD}$ progression (Cirrito et al., 2005, 2008). Optogenetics was also used to shed light onto the state of brain rhythms in AD. Optogenetic entrainment of interneurons in the gamma frequency range restored gamma oscillations and reduced $A \beta$ deposition in a mouse model of AD (Iaccarino et al., 2016). Our laboratory reported that light-activation of channelrhodopsin-2 (ChR2)expressing excitatory neurons at the endogenous frequency of slow waves in APP mice for 4 weeks rescued aberrant slow oscillations by restoring slow wave power. It also restored GABA as well as $\mathrm{GABA}_{\mathrm{A}}$ and $\mathrm{GABA}_{\mathrm{B}}$ receptor levels (Kastanenka et al., 2017). In addition, chronic restoration of SWA halted $\mathrm{A} \beta$ plaque deposition and prevented intraneuronal calcium elevations (defined as calcium overload) (Kastanenka et al., 2017). Alternatively, driving slow waves at twice the endogenous frequency using optogenetics augmented $A \beta$ production, increased neuronal calcium overload and decreased the synaptic spine density (Kastanenka et al., 2019). Optogenetic restoration of circuit activity slowed pathology progression in mouse models of $\mathrm{AD}$, while optogenetic increases in the frequency of slow waves accelerated the progressive pathophysiology and resulted in neuronal network failure.

Similarly, modulations of brain wave activity restored memory deficits in experimental models using optogenetics. Synchronization of SWA in somatosensory and motor cortices using optogenetics was able to restore perceptual memory impairment and prolong memory retention in sleep-deprived mice (Miyamoto et al., 2016). In addition, restoration of hippocampal oscillations with optogenetics resulted in an improvement of recognition memory in APP mice (Giovannetti et al., 2018). Also, optogenetic activation of memory engram cells in hippocampus increased spine density in engram cells and restored long-term memory (Roy et al., 2016). Furthermore, gamma oscillation rescue using optogenetics improved spatial memory in an AD mouse model (Etter et al., 2019). Restoring brain oscillations by optogenetic approaches in mouse models provides insight into novel therapeutic approaches to treat and/or prevent $\mathrm{AD}$ altogether. Animal studies suggest that restoring brain oscillation activity, including SWA, may be an effective therapeutic strategy for reducing memory deficits in $\mathrm{AD}$ patients.

\section{RESTORING SLOW WAVE SLEEP IS A PROMISING THERAPY FOR AD}

Currently, there are no effective treatments able to slow $A D$ progression and alleviate cognitive and memory impairments in patients. The majority of clinical therapeutic approaches focus on clearing $A \beta$ and tau with monoclonal antibodies using passive immunotherapies (van Dyck, 2018). Light therapy had mixed results in the clinic (Dowling et al., 2005, 2008; Riemersmavan der Lek et al., 2008). However, a large number of clinical trial failures underscores the need to identify novel therapeutic strategies for treating AD.

Restoration of SWA during NREM sleep in Alzheimer's patients might slow the disease progression and rescue sleepdependent memory consolidation. Transcranial direct current stimulation (tDCS) and transcranial magnetic stimulation (TMS) are two noninvasive brain stimulation methodologies that could potentially be used to do so. Recently, tDCS was applied to human MCI subjects during daytime nap to investigate the patterns of SWA and sleep-dependent memory consolidation. Both the slow oscillation power and memory performance were improved after stimulating the brain at the slow oscillation frequency with tDCS (Ladenbauer et al., 2017). Furthermore, repeated applications of tDCS induced slow oscillations during SWS and led to enhanced declarative memory retention the next day in older (Westerberg et al., 2015) and in young healthy adults (Marshall et al., 2004, 2006). In a similar study, TMS was used to evoke slow waves during NREM sleep. TMS increased SWA power in healthy young subjects (Massimini et al., 2007). In addition to tDCS and TMS methodologies, slow oscillations can be enhanced with auditory stimulation (Ngo et al., 2013; Leminen et al., 2017; Papalambros et al., 2017; Ong et al., 2018). Applied auditory tones that were phase-locked to the up states of slow oscillations during sleep benefited declarative memory consolidation in healthy young adults (Ngo et al., 2013; Leminen et al., 2017) and in older subjects (Papalambros et al., 2017). Furthermore, phase-locked acoustic stimulation also enhanced memory encoding during nap in healthy young subjects (Ong et al., 2018). Another sensory stimulation strategy visual stimulation, can be used to induce SWA (Riedner et al., 2011). Using high-density EEG recordings in healthy young subjects during NREM sleep, SWA was successfully evoked by visual stimuli (Riedner et al., 2011). Thus, tDCS, TMS, acoustic, and visual stimulations could potentially be used to enhance sleep-dependent memory consolidation in healthy subjects and $\mathrm{AD}$ patients in early stages of the disease. 
Targeting specific GABAergic neuronal circuit elements may be particularly attractive in designing new $\mathrm{AD}$ therapies. Whereas restoration of parvalbumin interneuron activity acutely restored gamma oscillations (Iaccarino et al., 2016) and prevented memory loss as well as network hyperexcitability (Hijazi et al., 2019), activation of either neuronal nitric oxide synthase (nNOS) or somatostatin neurons may be useful for restoring SWA. A recent study involving the chemogenetic activation of SSTpositive cells in the cerebral cortex showed increased SWA, elevated slope of individual slow waves, and prolonged NREM sleep duration compared to control conditions. Alternatively, chemogenetic inhibition of these cells reduced SWA and slowwave incidence without changing time spent in NREM sleep (Funk et al., 2017). We previously demonstrated that nNOS neurons are activated during episodes of NREM sleep associated with increased SWA (Gerashchenko et al., 2008). We also showed that optogenetically evoked responses in nNOS-positive cells of the cerebral cortex are consistent with their role in slowwave sleep physiology (Gerashchenko et al., 2018). Furthermore, mice lacking nNOS expression in SST positive neurons exhibited significant impairments in both homeostatic low delta frequency range SWA production and a recognition memory task that relies on cortical input (Zielinski et al., 2019). Further studies will determine whether activation of nNOS/somatostatin neurons in the cerebral cortex is efficient in reducing $\mathrm{AD}$ pathology, and whether this effect is mediated by SWA enhancement. Finally, instead of activating endogenous interneurons, it would be promising to explore cell-based therapeutic strategies, such as transplantation of human stem cell-derived interneurons to increase inhibitory tone and restore SWA.

\section{DISCUSSION}

In addition to memory disruptions, Alzheimer's patients experience disturbances in their sleep-wake cycles, due to increased nighttime wakefulness and decreased NREM SWS. $\mathrm{AD}$ pathology is correlated with SWA disruptions at the early stages of AD. Decreased SWA was found in asymptomatic cognitively normal adults and aMCI patients. Since slow oscillation disruption is an early event, it has the potential to be used as an early biomarker for AD. It should be noted that a lot of human studies discussed here were based on a low

\section{REFERENCES}

Abbott, N. J., Pizzo, M. E., Preston, J. E., Janigro, D., and Thorne, R. G. (2018). The role of brain barriers in fluid movement in the CNS: is there a "glymphatic" system? Acta Neuropathol. 135, 387-407. doi: 10.1007/s00401-0181812-4

Alzheimer's Association (2016). 2016 Alzheimer's disease facts and figures. Alzheimers Dement. J. Alzheimers Assoc. 12, 459-509. doi: 10.1016/j.jalz.2016. 03.001

Araque, A., Parpura, V., Sanzgiri, R. P., and Haydon, P. G. (1999). Tripartite synapses: glia, the unacknowledged partner. Trends Neurosci. 22, 208-215. doi: 10.1016/S0166-2236(98)01349-6

Aton, S. J., Seibt, J., Dumoulin, M., Jha, S. K., Steinmetz, N., Coleman, T., et al. (2009). Mechanisms of sleep-dependent consolidation of cortical plasticity. Neuron 61, 454-466. doi: 10.1016/j.neuron.2009.01.007 sample size at higher risk for false positives due to random variations in a small number of data points. Thus replications are needed to validate the findings. Nevertheless, disruptions in slow oscillations might underlie the memory impairments as part of $\mathrm{AD}$ progression, since SWA plays a key role in declarative memory consolidation during sleep. Moreover, animal models of $\mathrm{AD}$ recapitulate the slow wave disruptions and can be used for mechanistic studies. Use of leading-edge technologies, including optogenetics, wide-field imaging and multiphoton microscopy, in addition to traditional technologies, including electrophysiology, provided insight into the mechanisms of slow wave disruptions in AD. A better understanding of the relationship between SWA disruptions and memory decline may shed light on the mechanistic pathways underlying ADassociated memory impairment. SWA restoration provides a promising novel therapeutic target for AD. Utilizing noninvasive brain stimulation technologies and medications that upregulate inhibitory elements of cortico-thalamic circuits may prove to become efficient therapeutic strategies. Development of novel therapeutic interventions targeting SWA during NREM sleep early in the disease progression might slow memory decline in the elderly and delay AD onset in MCI or healthy individuals at risk for developing $\mathrm{AD}$.

\section{AUTHOR CONTRIBUTIONS}

YL and KK wrote the original draft of the manuscript. YL and KK prepared the figure. YL, DG, IT, BB, and KK reviewed and edited the final manuscript. All authors contributed to the article and approved the submitted version.

\section{FUNDING}

This work was supported by a grant from the Alzheimer's Association AARG-18-529336 and NIH RF1AG061774.

\section{ACKNOWLEDGMENTS}

We thank the donors of Alzheimer's Disease Research, a program of BrightFocus Foundation.

Backhaus, J., Born, J., Hoeckesfeld, R., Fokuhl, S., Hohagen, F., and Junghanns, K. (2007). Midlife decline in declarative memory consolidation is correlated with a decline in slow wave sleep. Learn. Mem. 14, 336-341. doi: 10.1101/lm.470507

Backhaus, J., Junghanns, K., Born, J., Hohaus, K., Faasch, F., and Hohagen, F. (2006). Impaired declarative memory consolidation during sleep in patients with primary insomnia: influence of sleep architecture and nocturnal cortisol release. Biol. Psychiatry 60, 1324-1330. doi: 10.1016/j.biopsych.2006.03.051

Bazhenov, M., Timofeev, I., Steriade, M., and Sejnowski, T. J. (2002). Model of thalamocortical slow-wave sleep oscillations and transitions to activated States. J. Neurosci. Off. J. Soc. Neurosci. 22, 8691-8704. doi: 10.1523/jneurosci.22-1908691.2002

Beaulieu-Laroche, L., Toloza, E. H. S., van der Goes, M.-S., Lafourcade, M., Barnagian, D., Williams, Z. M., et al. (2018). Enhanced dendritic compartmentalization in human cortical neurons. Cell 175, 643-651. doi: 10. 1016/j.cell.2018.08.045 
Bliwise, D. L., Hughes, M., McMahon, P. M., and Kutner, N. (1995). Observed sleep/wakefulness and severity of dementia in an Alzheimer's disease special care unit. J. Gerontol. A. Biol. Sci. Med. Sci. 50, M303-M306. doi: 10.1093/ gerona/50a.6.m 303

Bloom, G. S. (2014). Amyloid- $\beta$ and tau: the trigger and bullet in Alzheimer disease pathogenesis. JAMA Neurol. 71, 505-508. doi: 10.1001/jamaneurol.2013.5847

Born, J., and Wilhelm, I. (2012). System consolidation of memory during sleep. Psychol. Res. 76, 192-203. doi: 10.1007/s00426-011-0335-6

Boyden, E. S., Zhang, F., Bamberg, E., Nagel, G., and Deisseroth, K. (2005). Millisecond-timescale, genetically targeted optical control of neural activity. Nat. Neurosci. 8, 1263-1268. doi: 10.1038/nn1525

Brzecka, A., Leszek, J., Ashraf, G. M., Ejma, M., Ávila-Rodriguez, M. F., Yarla, N. S., et al. (2018). Sleep disorders associated with Alzheimer's disease: a perspective. Front. Neurosci. 12:330. doi: 10.3389/fnins.2018.00330

Busche, M. A., Eichhoff, G., Adelsberger, H., Abramowski, D., Wiederhold, K.-H., Haass, C., et al. (2008). Clusters of hyperactive neurons near amyloid plaques in a mouse model of Alzheimer's disease. Science 321, 1686-1689. doi: 10.1126/ science. 1162844

Busche, M. A., Kekuš, M., Adelsberger, H., Noda, T., Förstl, H., Nelken, I., et al. (2015). Rescue of long-range circuit dysfunction in Alzheimer's disease models. Nat. Neurosci. 18, 1623-1630. doi: 10.1038/nn.4137

Calderon-Garcidueñas, A. L., and Duyckaerts, C. (2017). Alzheimer disease. Handb. Clin. Neurol. 145, 325-337. doi: 10.1016/B978-0-12-802395-2.00023-7

Carskadon, M. A., and Dement, W. C. (2011). "Normal human sleep: an overview. Med. Clin. North Am. 88, 551-565. doi: 10.1016/j.mcna.2004.01.001

Cash, S. S., Halgren, E., Dehghani, N., Rossetti, A. O., Thesen, T., Wang, C., et al. (2009). The Human K-complex represents an isolated cortical down-State. Science 324, 1084-1087. doi: 10.1126/science.1169626

Castano-Prat, P., Perez-Mendez, L., Perez-Zabalza, M., Sanfeliu, C., GiménezLlort, L., and Sanchez-Vives, M. V. (2019). Altered slow $(<1 \mathrm{~Hz})$ and fast (beta and gamma) neocortical oscillations in the 3xTg-AD mouse model of Alzheimer's disease under anesthesia. Neurobiol. Aging 79, 142-151. doi: 10. 1016/j.neurobiolaging.2019.02.009

Chauvette, S., Seigneur, J., and Timofeev, I. (2012). Sleep oscillations in the thalamocortical system induce long-term neuronal plasticity. Neuron 75:1105. doi: 10.1016/j.neuron.2012.08.034

Chauvette, S., Volgushev, M., and Timofeev, I. (2010). Origin of active states in local neocortical networks during slow sleep oscillation. Cereb. Cortex 20, 2660-2674. doi: 10.1093/cercor/bhq009

Chen, J.-Y., Chauvette, S., Skorheim, S., Timofeev, I., and Bazhenov, M. (2012). Interneuron-mediated inhibition synchronizes neuronal activity during slow oscillation. J. Physiol. 590, 3987-4010. doi: 10.1113/jphysiol.2012.227462

Christos, G. A. (1993). Is Alzheimer's disease related to a deficit or malfunction of rapid eye movement (REM) sleep? Med. Hypotheses 41, 435-439. doi: 10.1016/ 0306-9877(93)90121-6

Cirrito, J. R., Kang, J.-E., Lee, J., Stewart, F. R., Verges, D. K., Silverio, L. M., et al. (2008). Endocytosis is required for synaptic activity-dependent release of amyloid-beta in vivo. Neuron 58, 42-51. doi: 10.1016/j.neuron.2008. 02.003

Cirrito, J. R., Yamada, K. A., Finn, M. B., Sloviter, R. S., Bales, K. R., May, P. C., et al. (2005). Synaptic activity regulates interstitial fluid amyloid-beta levels in vivo. Neuron 48, 913-922. doi: 10.1016/j.neuron.2005.10.028

Clarke, L. E., and Barres, B. A. (2013). Emerging roles of astrocytes in neural circuit development. Nat. Rev. Neurosci. 14, 311-321. doi: 10.1038/nrn3484

Contreras, D., and Steriade, M. (1995). Cellular basis of EEG slow rhythms: a study of dynamic corticothalamic relationships. J. Neurosci. 15, 604-622. doi: 10.1523/jneurosci.15-01-00604.1995

Csercsa, R., Dombovári, B., Fabó, D., Wittner, L., Eross, L., Entz, L., et al. (2010). Laminar analysis of slow wave activity in humans. Brain J. Neurol. 133, 28142829. doi: 10.1093/brain/awq169

Cummings, J. L., Tong, G., and Ballard, C. (2019). Treatment combinations for Alzheimer's disease: current and future pharmacotherapy options. J. Alzheimers Dis. 67, 779-794. doi: 10.3233/JAD-180766

David, F., Schmiedt, J. T., Taylor, H. L., Orban, G., Di Giovanni, G., Uebele, V. N., et al. (2013). Essential thalamic contribution to slow waves of natural sleep. J. Neurosci. Off. J. Soc. Neurosci. 33, 19599-19610. doi: 10.1523/JNEUROSCI. 3169-13.2013
DeKosky, S. T., and Scheff, S. W. (1990). Synapse loss in frontal cortex biopsies in Alzheimer's disease: correlation with cognitive severity. Ann. Neurol. 27, 457-464. doi: 10.1002/ana.410270502

Diekelmann, S., and Born, J. (2010). The memory function of sleep. Nat. Rev. Neurosci. 11, 114-126. doi: 10.1038/nrn2762

Dowling, G. A., Burr, R. L., Van Someren, E. J. W., Hubbard, E. M., Luxenberg, J. S., Mastick, J., et al. (2008). Melatonin and bright-light treatment for rest-activity disruption in institutionalized patients with Alzheimer's disease. J. Am. Geriatr. Soc. 56, 239-246. doi: 10.1111/j.1532-5415.2007.01543.x

Dowling, G. A., Hubbard, E. M., Mastick, J., Luxenberg, J. S., Burr, R. L., and Van Someren, E. J. W. (2005). Effect of morning bright light treatment for restactivity disruption in institutionalized patients with severe Alzheimer's disease. Int. Psychogeriatr. 17, 221-236. doi: 10.1017/s1041610205001584

Etter, G., Veldt, S., van der Manseau, F., Zarrinkoub, I., Trillaud-Doppia, E., and Williams, S. (2019). Optogenetic gamma stimulation rescues memory impairments in an Alzheimer's disease mouse model. Nat. Commun. 10, 1-11. doi: 10.1038/s41467-019-13260-9

Fenno, L., Yizhar, O., and Deisseroth, K. (2011). The development and application of optogenetics. Annu. Rev. Neurosci. 34, 389-412. doi: 10.1146/annurevneuro-061010-113817

Fiáth, R., Kerekes, B. P., Wittner, L., Tóth, K., Beregszászi, P., Horváth, D., et al. (2016). Laminar analysis of the slow wave activity in the somatosensory cortex of anesthetized rats. Eur. J. Neurosci. 44, 1935-1951. doi: 10.1111/ejn.13274

Förstl, H., and Kurz, A. (1999). Clinical features of Alzheimer's disease. Eur. Arch. Psychiatry Clin. Neurosci. 249, 288-290. doi: 10.1007/s004060050101

Funk, C. M., Peelman, K., Bellesi, M., Marshall, W., Cirelli, C., and Tononi, G. (2017). Role of somatostatin-positive cortical interneurons in the generation of sleep slow waves. J. Neurosci. Off. J. Soc. Neurosci. 37, 9132-9148. doi: 10.1523/ JNEUROSCI.1303-17.2017

Galea, E., Morrison, W., Hudry, E., Arbel-Ornath, M., Bacskai, B. J., Gómez-Isla, T., et al. (2015). Topological analyses in APP/PS1 mice reveal that astrocytes do not migrate to amyloid- $\beta$ plaques. Proc. Natl. Acad. Sci. U.S.A. 112, 15556-15561. doi: $10.1073 /$ pnas.1516779112

Gerashchenko, D., Schmidt, M. A., Zielinski, M. R., Moore, M. E., and Wisor, J. P. (2018). Sleep state dependence of optogenetically evoked responses in neuronal nitric oxide synthase-positive cells of the cerebral cortex. Neuroscience 379, 189-201. doi: 10.1016/j.neuroscience.2018.02.006

Gerashchenko, D., Wisor, J. P., Burns, D., Reh, R. K., Shiromani, P. J., Sakurai, T., et al. (2008). Identification of a population of sleep-active cerebral cortex neurons. Proc. Natl. Acad. Sci. U.S.A. 105, 10227-10232. doi: 10.1073/pnas. 0803125105

Giovannetti, E. A., Poll, S., Justus, D., Kaneko, H., Fuhrmann, F., Steffen, J., et al. (2018). Restoring memory by optogenetic synchronization of hippocampal oscillations in an Alzheimer's disease mouse model. bioRxiv [Preprint], doi: $10.1101 / 363820$

Haider, B., Duque, A., Hasenstaub, A. R., and McCormick, D. A. (2006). Neocortical network activity in vivo is generated through a dynamic balance of excitation and inhibition. J. Neurosci. Off. J. Soc. Neurosci. 26, 4535-4545. doi: 10.1523/JNEUROSCI.5297-05.2006

Haider, B., Häusser, M., and Carandini, M. (2013). Inhibition dominates sensory responses in the awake cortex. Nature 493, 97-100. doi: 10.1038/nature11665

Haider, B., and McCormick, D. A. (2009). Rapid neocortical dynamics: cellular and network mechanisms. Neuron 62, 171-189. doi: 10.1016/j.neuron.2009.04.008

Hardy, J. A., and Higgins, G. A. (1992). Alzheimer's disease: the amyloid cascade hypothesis. Science 256, 184-185. doi: 10.1126/science.1566067

Henstridge, C. M., Hyman, B. T., and Spires-Jones, T. L. (2019). Beyond the neuron-cellular interactions early in Alzheimer disease pathogenesis. Nat. Rev. Neurosci. 20, 94-108. doi: 10.1038/s41583-018-0113-1

Hijazi, S., Heistek, T. S., Scheltens, P., Neumann, U., Shimshek, D. R., Mansvelder, H. D., et al. (2019). Early restoration of parvalbumin interneuron activity prevents memory loss and network hyperexcitability in a mouse model of Alzheimer's disease. Mol. Psychiatry doi: 10.1038/s41380-019-0483-4 [Epub ahead of print].

Hinard, V., Mikhail, C., Pradervand, S., Curie, T., Houtkooper, R. H., Auwerx, J., et al. (2012). Key electrophysiological, molecular, and metabolic signatures of sleep and wakefulness revealed in primary cortical cultures. J. Neurosci. Off. J. Soc. Neurosci. 32, 12506-12517. doi: 10.1523/JNEUROSCI.2306-12.2012 
Holth, J. K., Mahan, T. E., Robinson, G. O., Rocha, A., and Holtzman, D. M. (2017). Altered sleep and EEG power in the P301S Tau transgenic mouse model. Ann. Clin. Transl. Neurol. 4, 180-190. doi: 10.1002/acn3.390

Iaccarino, H. F., Singer, A. C., Martorell, A. J., Rudenko, A., Gao, F., Gillingham, T. Z., et al. (2016). Gamma frequency entrainment attenuates amyloid load and modifies microglia. Nature 540, 230-235. doi: 10.1038/nature20587

Iber, C., Ancoli-Israel, S., Chesson, A. L., and Quan, S. F. (2007). The AASM Manual For The Scoring Of Sleep And Associated Events: Rules, Terminology And Technical Specifications. Westchester, IL: American Academy of Sleep Medicine.

Iliff, J. J., Wang, M., Liao, Y., Plogg, B. A., Peng, W., Gundersen, G. A., et al. (2012). A paravascular pathway facilitates CSF flow through the brain parenchyma and the clearance of interstitial solutes, including amyloid $\beta$. Sci. Transl. Med. 4:147ra111. doi: 10.1126/scitranslmed.3003748

Jasinska, M., Grzegorczyk, A., Woznicka, O., Jasek, E., Kossut, M., BarbackaSurowiak, G., et al. (2015). Circadian rhythmicity of synapses in mouse somatosensory cortex. Eur. J. Neurosci. 42, 2585-2594. doi: 10.1111/ejn.13045

Ju, Y.-E. S., McLeland, J. S., Toedebusch, C. D., Xiong, C., Fagan, A. M., Duntley, S. P., et al. (2013). Sleep quality and preclinical Alzheimer disease. JAMA Neurol. 70, 587-593. doi: 10.1001/jamaneurol.2013.2334

Kang, J.-E., Lim, M. M., Bateman, R. J., Lee, J. J., Smyth, L. P., Cirrito, J. R., et al. (2009). Amyloid-beta dynamics are regulated by orexin and the sleep-wake cycle. Science 326, 1005-1007. doi: 10.1126/science.1180962

Kastanenka, K. V., Calvo-Rodriguez, M., Hou, S. S., Zhou, H., Takeda, S., ArbelOrnath, M., et al. (2019). Frequency-dependent exacerbation of Alzheimer's disease neuropathophysiology. Sci. Rep. 9:8964. doi: 10.1038/s41598-01944964-z

Kastanenka, K. V., Hou, S. S., Shakerdge, N., Logan, R., Wegmann, S., Chopra, V., et al. (2017). Optogenetic restoration of disrupted slow oscillations halts amyloid deposition and restores calcium homeostasis in an animal model of Alzheimer's disease. PLoS One 12:e170275. doi: 10.1371/journal.pone.0170275

Kastanenka, K. V., Moreno-Bote, R., Pittà, M. D., Perea, G., Eraso-Pichot, A., Masgrau, R., et al. (2020). A roadmap to integrate astrocytes into systems neuroscience. Glia 68, 5-26. doi: 10.1002/glia.23632

Kent, B. A., Strittmatter, S. M., and Nygaard, H. B. (2018). Sleep and EEG power spectral analysis in three transgenic mouse models of Alzheimer's disease: APP/PS1, 3xTgAD, and Tg2576. J. Alzheimers Dis. JAD 64, 1325-1336. doi: 10.3233/JAD- 180260

Kuchibhotla, K. V., Lattarulo, C. R., Hyman, B. T., and Bacskai, B. J. (2009). Synchronous hyperactivity and intercellular calcium waves in astrocytes in Alzheimer mice. Science 323, 1211-1215. doi: 10.1126/science.1169096

Ladenbauer, J., Ladenbauer, J., Külzow, N., Boor, R., de Avramova, E., Grittner, U., et al. (2017). Promoting sleep oscillations and their functional coupling by transcranial stimulation enhances memory consolidation in mild cognitive impairment. J. Neurosci. 37, 7111-7124. doi: 10.1523/JNEUROSCI.0260-17. 2017

Lemieux, M., Chauvette, S., and Timofeev, I. (2015). Neocortical inhibitory activities and long-range afferents contribute to the synchronous onset of silent states of the neocortical slow oscillation. J. Neurophysiol. 113, 768-779. doi: 10.1152/jn.00858.2013

Lemieux, M., Chen, J.-Y., Lonjers, P., Bazhenov, M., and Timofeev, I. (2014). The impact of cortical deafferentation on the neocortical slow oscillation. J. Neurosci. Off. J. Soc. Neurosci. 34, 5689-5703. doi: 10.1523/JNEUROSCI. 1156-13.2014

Leminen, M. M., Virkkala, J., Saure, E., Paajanen, T., Zee, P. C., Santostasi, G., et al. (2017). Enhanced memory consolidation via automatic sound stimulation during Non-REM sleep. Sleep 40:zsx003. doi: 10.1093/sleep/zsx003

Li, X., Gutierrez, D. V., Hanson, M. G., Han, J., Mark, M. D., Chiel, H., et al. (2005). Fast noninvasive activation and inhibition of neural and network activity by vertebrate rhodopsin and green algae channelrhodopsin. Proc. Natl. Acad. Sci. U.S.A. 102, 17816-17821. doi: 10.1073/pnas.0509030102

Lu, W., and Göder, R. (2012). Does abnormal non-rapid eye movement sleep impair declarative memory consolidation? Disturbed thalamic functions in sleep and memory processing. Sleep Med. Rev. 16, 389-394. doi: 10.1016/j.smrv. 2011.08.001

Lucey, B. P., Mawuenyega, K. G., Patterson, B. W., Elbert, D. L., Ovod, V., Kasten, T., et al. (2017). Associations between $\beta$-amyloid kinetics and the $\beta$-amyloid diurnal pattern in the central nervous system. JAMA Neurol. 74, 207-215. doi: 10.1001/jamaneurol.2016.4202
Lucey, B. P., McCullough, A., Landsness, E. C., Toedebusch, C. D., McLeland, J. S., Zaza, A. M., et al. (2019). Reduced non-rapid eye movement sleep is associated with tau pathology in early Alzheimer's disease. Sci. Transl. Med. 11:aau6550. doi: 10.1126/scitranslmed.aau6550

Mander, B. A., Marks, S. M., Vogel, J. W., Rao, V., Lu, B., Saletin, J. M., et al. (2015). $\beta$-amyloid disrupts human NREM slow waves and related hippocampusdependent memory consolidation. Nat. Neurosci. 18, 1051-1057. doi: 10.1038/ nn. 4035

Mander, B. A., Rao, V., Lu, B., Saletin, J. M., Lindquist, J. R., Ancoli-Israel, S., et al. (2013). Prefrontal atrophy, disrupted NREM slow waves, and impaired hippocampal-dependent memory in aging. Nat. Neurosci. 16, 357-364. doi: $10.1038 / \mathrm{nn} .3324$

Marshall, L., Helgadóttir, H., Mölle, M., and Born, J. (2006). Boosting slow oscillations during sleep potentiates memory. Nature 444, 610-613. doi: 10. 1038/nature05278

Marshall, L., Mölle, M., Hallschmid, M., and Born, J. (2004). Transcranial direct current stimulation during sleep improves declarative memory. J. Neurosci. 24, 9985-9992. doi: 10.1523/JNEUROSCI.2725-04.2004

Massimini, M., Ferrarelli, F., Esser, S. K., Riedner, B. A., Huber, R., Murphy, M., et al. (2007). Triggering sleep slow waves by transcranial magnetic stimulation. Proc. Natl. Acad. Sci. U.S.A. 104, 8496-8501. doi: 10.1073/pnas.0702495104

Massimini, M., Huber, R., Ferrarelli, F., Hill, S., and Tononi, G. (2004). The sleep slow oscillation as a traveling wave. J. Neurosci. Off. J. Soc. Neurosci. 24, 6862-6870. doi: 10.1523/JNEUROSCI.1318-04.2004

McCurry, S. M., Logsdon, R. G., Teri, L., Gibbons, L. E., Kukull, W. A., Bowen, J. D., et al. (1999). Characteristics of sleep disturbance in community-dwelling Alzheimer's disease patients. J. Geriatr. Psychiatry Neurol. 12, 53-59. doi: 10. $1177 / 089198879901200203$

Milojkovic, B. A., Zhou, W.-L., and Antic, S. D. (2007). Voltage and calcium transients in basal dendrites of the rat prefrontal cortex. J. Physiol. 585:447. doi: 10.1113/jphysiol.2007.142315

Miyamoto, D., Hirai, D., Fung, C. C. A., Inutsuka, A., Odagawa, M., Suzuki, T., et al. (2016). Top-down cortical input during NREM sleep consolidates perceptual memory. Science 352, 1315-1318. doi: 10.1126/science.aaf0902

Moe, K. E., Vitiello, M. V., Larsen, L. H., and Prinz, P. N. (1995). Sleep/wake patterns In Alzheimer's disease: relationships with cognition and function. J. Sleep Res. 4, 15-20. doi: 10.1111/j.1365-2869.1995.tb00145.x

Mohajerani, M. H., McVea, D. A., Fingas, M., and Murphy, T. H. (2010). Mirrored bilateral slow-wave cortical activity within local circuits revealed by fast bihemispheric voltage-sensitive dye imaging in anesthetized and awake mice. J. Neurosci. 30, 3745-3751. doi: 10.1523/JNEUROSCI.6437-09.2010

Mohan, H., Verhoog, M. B., Doreswamy, K. K., Eyal, G., Aardse, R., Lodder, B. N., et al. (2015). Dendritic and axonal architecture of individual pyramidal neurons across layers of adult human neocortex. Cereb. Cortex 25, 4839-4853. doi: $10.1093 /$ cercor/bhv188

Moran, M., Lynch, C. A., Walsh, C., Coen, R., Coakley, D., and Lawlor, B. A. (2005). Sleep disturbance in mild to moderate Alzheimer's disease. Sleep Med. 6, 347-352. doi: 10.1016/j.sleep.2004.12.005

Narikiyo, K., Mizuguchi, R., Ajima, A., Mitsui, S., Shiozaki, M., Hamanaka, H., et al. (2018). The claustrum coordinates cortical slow-wave activity. Nat. Neurosci. doi: 10.1101/286773 [Epub ahead of print],

Newman, E. A. (2003). New roles for astrocytes: regulation of synaptic transmission. Trends Neurosci. 26, 536-542. doi: 10.1016/S0166-2236(03) 00237-6

Ngo, H.-V. V., Martinetz, T., Born, J., and Mölle, M. (2013). Auditory closed-loop stimulation of the sleep slow oscillation enhances memory. Neuron 78, 545-553. doi: 10.1016/j.neuron.2013.03.006

Niethard, N., Ngo, H.-V. V., Ehrlich, I., and Born, J. (2018). Cortical circuit activity underlying sleep slow oscillations and spindles. Proc. Natl. Acad. Sci. U.S.A. 115, E9220-E9229. doi: 10.1073/pnas.1805517115

Ong, J. L., Patanaik, A., Chee, N. I. Y. N., Lee, X. K., Poh, J.-H., and Chee, M. W. L. (2018). Auditory stimulation of sleep slow oscillations modulates subsequent memory encoding through altered hippocampal function. Sleep 41:zsy031. doi: 10.1093/sleep/zsy031

Papalambros, N. A., Santostasi, G., Malkani, R. G., Braun, R., Weintraub, S., Paller, K. A., et al. (2017). Acoustic enhancement of sleep slow oscillations and concomitant memory improvement in older adults. Front. Hum. Neurosci. 11:109. doi: 10.3389/fnhum.2017.00109 
Pase, M. P., Himali, J. J., Grima, N. A., Beiser, A. S., Satizabal, C. L., Aparicio, H. J., et al. (2017). Sleep architecture and the risk of incident dementia in the community. Neurology 89, 1244-1250. doi: 10.1212/WNL.0000000000004373

Poskanzer, K. E., and Yuste, R. (2011). Astrocytic regulation of cortical UP states. Proc. Natl. Acad. Sci. U.S.A. 108, 18453-18458. doi: 10.1073/pnas.1112378108

Poskanzer, K. E., and Yuste, R. (2016). Astrocytes regulate cortical state switching in vivo. Proc. Natl. Acad. Sci. U.S.A. 113, E2675-E2684. doi: 10.1073/pnas. 1520759113

Prinz, P. N., Peskind, E. R., Vitaliano, P. P., Raskind, M. A., Eisdorfer, C., Zemcuznikov, H. N., et al. (1982). Changes in the sleep and waking EEGs of nondemented and demented elderly subjects. J. Am. Geriatr. Soc. 30, 86-92. doi: 10.1111/j.1532-5415.1982.tb01279.x

Rasch, B., and Born, J. (2013). About sleep's role in memory. Physiol. Rev. 93, 681-766. doi: 10.1152/physrev.00032.2012

Rauchs, G., Schabus, M., Parapatics, S., Bertran, F., Clochon, P., Hot, P., et al. (2008). Is there a link between sleep changes and memory in Alzheimer's disease? Neuroreport 19, 1159-1162. doi: 10.1097/WNR.0b013e32830867c4

Riedner, B. A., Hulse, B. K., Murphy, M. J., Ferrarelli, F., and Tononi, G. (2011). Temporal dynamics of cortical sources underlying spontaneous and peripherally evoked slow waves. Prog. Brain Res. 193, 201-218. doi: 10.1016/ B978-0-444-53839-0.00013-2

Riemersma-van der Lek, R. F., Swaab, D. F., Twisk, J., Hol, E. M., Hoogendijk, W. J. G., and Van Someren, E. J. W. (2008). Effect of bright light and melatonin on cognitive and noncognitive function in elderly residents of group care facilities: a randomized controlled trial. JAMA 299, 2642-2655. doi: 10.1001/ jama.299.22.2642

Robinson, S. R. (2000). Neuronal expression of glutamine synthetase in Alzheimer's disease indicates a profound impairment of metabolic interactions with astrocytes. Neurochem. Int. 36, 471-482. doi: 10.1016/S0197-0186(99)00150-3

Roh, J. H., Huang, Y., Bero, A. W., Kasten, T., Stewart, F. R., Bateman, R. J., et al. (2012). Sleep-wake cycle and diurnal fluctuation of amyloid- $\beta$ as biomarkers of brain amyloid pathology. Sci. Transl. Med. 4:150ra122. doi: 10.1126/ scitranslmed.3004291

Roy, D. S., Arons, A., Mitchell, T. I., Pignatelli, M., Ryan, T. J., and Tonegawa, S. (2016). Memory retrieval by activating engram cells in mouse models of early Alzheimer's disease. Nature 531, 508-512. doi: 10.1038/nature17172

Rudolph, M., Pospischil, M., Timofeev, I., and Destexhe, A. (2007). Inhibition determines membrane potential dynamics and controls action potential generation in awake and sleeping cat cortex. J. Neurosci. Off. J. Soc. Neurosci. 27, 5280-5290. doi: 10.1523/JNEUROSCI.4652-06.2007

Sanchez-Vives, M. V., Mattia, M., Compte, A., Perez-Zabalza, M., Winograd, M., Descalzo, V. F., et al. (2010). Inhibitory modulation of cortical up states. J. Neurophysiol. 104, 1314-1324. doi: 10.1152/jn.00178.2010

Sanchez-Vives, M. V., and McCormick, D. A. (2000). Cellular and network mechanisms of rhythmic recurrent activity in neocortex. Nat. Neurosci. 3, 1027-1034. doi: 10.1038/79848

Schallier, A., Smolders, I., Van Dam, D., Loyens, E., De Deyn, P. P., Michotte, A., et al. (2011). Region- and age-specific changes in glutamate transport in the A $\beta$ PP23 mouse model for Alzheimer's disease. J. Alzheimers Dis. JAD 24, 287-300. doi: 10.3233/JAD-2011-101005

Seibt, J., Dumoulin, M. C., Aton, S. J., Coleman, T., Watson, A., Naidoo, N., et al. (2012). Protein synthesis during sleep consolidates cortical plasticity in vivo. Curr. Biol. CB 22, 676-682. doi: 10.1016/j.cub.2012.02.016

Seibt, J., and Frank, M. G. (2019). Primed to sleep: the dynamics of synaptic plasticity across brain states. Front. Syst. Neurosci. 13:2. doi: 10.3389/fnsys.2019. 00002

Seibt, J., Richard, C. J., Sigl-Glöckner, J., Takahashi, N., Kaplan, D. I., Doron, G., et al. (2017). Cortical dendritic activity correlates with spindle-rich oscillations during sleep in rodents. Nat. Commun. 8, 1-13. doi: 10.1038/s41467-01700735-w

Selkoe, D. J. (2019). Early network dysfunction in Alzheimer's disease. Science 365, 540-541. doi: 10.1126/science.aay5188

Selkoe, D. J., and Hardy, J. (2016). The amyloid hypothesis of Alzheimer's disease at 25 years. EMBO Mol. Med. 8, 595-608. doi: 10.15252/emmm.201606210

Sheroziya, M., and Timofeev, I. (2014). Global intracellular slow-wave dynamics of the thalamocortical system. J. Neurosci. Off. J. Soc. Neurosci. 34, 8875-8893. doi: 10.1523/JNEUROSCI.4460-13.2014
Soltani, S., Chauvette, S., Bukhtiyarova, O., Lina, J.-M., Dubé, J., Seigneur, J., et al. (2019). Sleep-wake cycle in young and older mice. Front. Syst. Neurosci. 13:51. doi: 10.3389/fnsys.2019.00051

Spira, A. P., Gamaldo, A. A., An, Y., Wu, M. N., Simonsick, E. M., Bilgel, M., et al. (2013). Self-reported sleep and $\beta$-amyloid deposition in community-dwelling older adults. JAMA Neurol. 70, 1537-1543. doi: 10.1001/jamaneurol.2013.4258

Spires-Jones, T. L., and Hyman, B. T. (2014). The intersection of amyloid beta and tau at synapses in Alzheimer's disease. Neuron 82, 756-771. doi: 10.1016/j. neuron.2014.05.004

Steriade, M., Contreras, D., Curró Dossi, R., and Nuñez, A. (1993a). The slow (< $1 \mathrm{~Hz}$ ) oscillation in reticular thalamic and thalamocortical neurons: scenario of sleep rhythm generation in interacting thalamic and neocortical networks. J. Neurosci. Off. J. Soc. Neurosci. 13, 3284-3299. doi: 10.1523/jneurosci.13-0803284.1993

Steriade, M., Nunez, A., and Amzica, F. (1993b). A novel slow ( $<1 \mathrm{~Hz}$ ) oscillation of neocortical neurons in vivo: depolarizing and hyperpolarizing components. J. Neurosci. 13, 3252-3265. doi: 10.1523/JNEUROSCI.13-08-03252.1993

Steriade, M., Nuñez, A., and Amzica, F. (1993c). Intracellular analysis of relations between the slow $(<1 \mathrm{~Hz})$ neocortical oscillation and other sleep rhythms of the electroencephalogram. J. Neurosci. Off. J. Soc. Neurosci. 13, 3266-3283. doi: 10.1523/jneurosci.13-08-03266.1993

Steriade, M., and Timofeev, I. (2003). Neuronal plasticity in thalamocortical networks during sleep and waking oscillations. Neuron 37, 563-576. doi: 10. 1016/S0896-6273(03)00065-5

Steriade, M., Timofeev, I., and Grenier, F. (2001). Natural waking and sleep states: a view from inside neocortical neurons. J. Neurophysiol. 85, 1969-1985. doi: 10.1152/jn.2001.85.5.1969

Sun, J.-J., Kilb, W., and Luhmann, H. J. (2010). Self-organization of repetitive spike patterns in developing neuronal networks in vitro. Eur. J. Neurosci. 32, 1289-1299. doi: 10.1111/j.1460-9568.2010.07383.x

Szabó, Z., Héja, L., Szalay, G., Kékesi, O., Füredi, A., Szebényi, K., et al. (2017). Extensive astrocyte synchronization advances neuronal coupling in slow wave activity in vivo. Sci. Rep. 7:6018. doi: 10.1038/s41598-017-06073-7

Timofeev, I., and Chauvette, S. (2017). Sleep slow oscillation and plasticity. Curr. Opin. Neurobiol. 44, 116-126. doi: 10.1016/j.conb.2017.03.019

Timofeev, I., Contreras, D., and Steriade, M. (1996). Synaptic responsiveness of cortical and thalamic neurones during various phases of slow sleep oscillation in cat. J. Physiol. 494, 265-278. doi: 10.1113/jphysiol.1996.sp021489

Timofeev, I., Grenier, F., Bazhenov, M., Sejnowski, T. J., and Steriade, M. (2000a). Origin of slow cortical oscillations in deafferented cortical slabs. Cereb. Cortex 10, 1185-1199. doi: 10.1093/cercor/10.12.1185

Timofeev, I., Grenier, F., and Steriade, M. (2000b). Impact of intrinsic properties and synaptic factors on the activity of neocortical networks in vivo. J. Physiol. Paris 94, 343-355. doi: 10.1016/s0928-4257(00)01097-4

Timofeev, I., Grenier, F., and Steriade, M. (2001). Disfacilitation and active inhibition in the neocortex during the natural sleep-wake cycle: an intracellular study. Proc. Natl. Acad. Sci. U.S.A. 98, 1924-1929. doi: 10.1073/pnas.98.4.1924

Timofeev, I., Schoch, S. F., LeBourgeois, M. K., Huber, R., Riedner, B. A., and Kurth, S. (2020). Spatio-temporal properties of sleep slow waves and implications for development. Curr. Opin. Physiol. 15, 172-182. doi: 10.1016/j.cophys.2020.01. 007

Timofeev, I., and Steriade, M. (1996). Low-frequency rhythms in the thalamus of intact-cortex and decorticated cats. J. Neurophysiol. 76, 4152-4168. doi: 10.1152/jn.1996.76.6.4152

Tononi, G., and Cirelli, C. (2003). Sleep and synaptic homeostasis: a hypothesis. Brain Res. Bull. 62, 143-150. doi: 10.1016/j.brainresbull.2003.09.004

Tononi, G., and Cirelli, C. (2014). Sleep and the price of plasticity: from synaptic and cellular homeostasis to memory consolidation and integration. Neuron 81:12. doi: 10.1016/j.neuron.2013.12.025

Van Cauter, E., Leproult, R., and Plat, L. (2000). Age-related changes in slow wave sleep and REM sleep and relationship with growth hormone and cortisol levels in healthy men. JAMA 284, 861-868. doi: 10.1001/jama.284.7.861

van Dyck, C. H. (2018). Anti-amyloid- $\beta$ monoclonal antibodies for Alzheimer's disease: pitfalls and promise. Biol. Psychiatry 83, 311-319. doi: 10.1016/j. biopsych.2017.08.010

Vitiello, M. V., and Prinz, P. N. (1989). Alzheimer's disease. Sleep and sleep/wake patterns. Clin. Geriatr. Med. 5, 289-299. 
Volgushev, M., Chauvette, S., Mukovski, M., and Timofeev, I. (2006). Precise longrange synchronization of activity and silence in neocortical neurons during slow-wave oscillations [corrected]. J. Neurosci. Off. J. Soc. Neurosci. 26, 56655672. doi: 10.1523/JNEUROSCI.0279-06.2006

Walker, M. P. (2009). The role of slow wave sleep in memory processing. J. Clin. Sleep Med. JCSM Off. Publ. Am. Acad. Sleep Med. 5, S20-S26.

Westerberg, C. E., Florczak, S. M., Weintraub, S., Mesulam, M.-M., Marshall, L., Zee, P. C., et al. (2015). Memory improvement via slow oscillatory stimulation during sleep in older adults. Neurobiol. Aging 36, 2577-2586. doi: 10.1016/j. neurobiolaging.2015.05.014

Westerberg, C. E., Mander, B. A., Florczak, S. M., Weintraub, S., Mesulam, M.M., Zee, P. C., et al. (2012). Concurrent impairments in sleep and memory in amnestic mild cognitive impairment. J. Int. Neuropsychol. Soc. JINS 18, 490-500. doi: 10.1017/S135561771200001X

Winer, J. R., Mander, B. A., Helfrich, R. F., Maass, A., Harrison, T. M., Baker, S. L., et al. (2019). Sleep as a potential biomarker of tau and $\beta$-amyloid burden in the human brain. J. Neurosci. Off. J. Soc. Neurosci. 39, 6315-6324. doi: 10.1523/ JNEUROSCI.0503-19.2019

Wu, J. W., Hussaini, S. A., Bastille, I. M., Rodriguez, G. A., Mrejeru, A., Rilett, K., et al. (2016). Neuronal activity enhances tau propagation and tau pathology in vivo. Nat. Neurosci. 19, 1085-1092. doi: 10.1038/nn.4328

Xie, L., Kang, H., Xu, Q., Chen, M. J., Liao, Y., Thiyagarajan, M., et al. (2013). Sleep drives metabolite clearance from the adult brain. Science 342, 373-377. doi: 10.1126/science.1241224

Yamamoto, K., Tanei, Z., Hashimoto, T., Wakabayashi, T., Okuno, H., Naka, Y., et al. (2015). Chronic optogenetic activation augments $A \beta$ pathology in a mouse model of Alzheimer disease. Cell Rep. 11, 859-865. doi: 10.1016/j.celrep.2015. 04.017
Yang, G., Lai, C. S. W., Cichon, J., Ma, L., Li, W., and Gan, W.B. (2014). Sleep promotes branch-specific formation of dendritic spines after learning. Science 344, 1173-1178. doi: 10.1126/science.124 9098

Yiannopoulou, K. G., and Papageorgiou, S. G. (2013). Current and future treatments for Alzheimer's disease. Ther. Adv. Neurol. Disord. 6, 19-33. doi: $10.1177 / 1756285612461679$

Zielinski, M. R., Atochin, D. N., McNally, J. M., McKenna, J. T., Huang, P. L., Strecker, R. E., et al. (2019). Somatostatin $+/$ nNOS+ neurons are involved in delta electroencephalogram activity and corticaldependent recognition memory. Sleep 42:zsz143. doi: 10.1093/sleep/zs z143

Zucca, S., Pasquale, V., Lagomarsino de Leon Roig, P., Panzeri, S., and Fellin, T. (2019). Thalamic drive of cortical parvalbumin-positive interneurons during down states in anesthetized mice. Curr. Biol. CB 29, 1481-1490. doi: 10.1016/j. cub.2019.04.007

Conflict of Interest: The authors declare that the research was conducted in the absence of any commercial or financial relationships that could be construed as a potential conflict of interest.

Copyright (c) 2020 Lee, Gerashchenko, Timofeev, Bacskai and Kastanenka. This is an open-access article distributed under the terms of the Creative Commons Attribution License (CC BY). The use, distribution or reproduction in other forums is permitted, provided the original author(s) and the copyright owner(s) are credited and that the original publication in this journal is cited, in accordance with accepted academic practice. No use, distribution or reproduction is permitted which does not comply with these terms. 